\section{AB0719 BASELINE CHARACTERISTIC OF NEWLY DIAGNOSED PATIENTS WITH AXIAL SPONDYLOARTHRITIS: RESULTS FROM THE SINGLE CENTRE LITHUANIAN COHORT}

J. Sabaliauskiene ${ }^{1}$, A. Baranauskaite ${ }^{2}$. ${ }^{1}$ Rheumatology; ${ }^{2}$ Lithuanian University of Health Sciences, Kaunas, Lithuania

Background: The prevalence rates for spondyloarthropathies has been investigated in an epidemiological study in Lithuania (1), but no studies are analysing the demographics, clinical characteristics of SpA in Lithuania. Changes in spondyloarthritis $(\mathrm{SpA})$ concept and application of the new criteria for classification should improve spondyloarthritis diagnostic standards in routine clinical practice. Objectives: To assess demographics and clinical manifestations of firstly diagnosed axial spondyloarthritis, to compare ankylosing spondylitis (AS) with non-radiographic axial spondyloarthritis (nr-axSpA) using standardized clinical assessment tools.

Methods: In September 2014 our centre began to collect a cohort of patients with newly diagnosed axial spondyloarthritis, according to ASAS criteria. Statistical analysis was performed with SPSS 20.0. A $p<0,05$ was considered statistically significant.

Results: 97 patients (60 men, 37 women) have been included. All of them $(100 \%)$ suffered from chronic back pain. Inflammatory back pain (according to ASAS criteria) was present in $77 \%$. $34(35,1 \%)$ patients already had definite radiographic changes in the sacroiliac joints (SIJ), therefore AS (based on modified New York criteria) was diagnosed. The mean age at first visit was similar: $34,3( \pm 10,0)$ in $\mathrm{nr}-\mathrm{axSpA}$ and $36,1( \pm 11,0)$ in AS group. Duration of symptoms was significantly longer in AS group (mean 106,6 months in AS versus 44,8 months in nr-axSpA). The prevalence of HLA-B27 was similar: $74,6 \%$ vs $91.2 \%$ for $n r-a x S p A$ and AS, respectively. There were more males in AS group (76,5\% vs $54,0 \%$, $p 0,03$ ). The frequency of clinical features (peripheral arthritis, dactylitis) and extra-articular manifestations (enthesitis, uveitis, psoriasis, inflammatory bowel disease, preceding infection) was similar between the two subgroups $(p>0,05)$. Mobility was slightly more impaired in AS patients, but it did not reach a significant level. No differences in the level of global pain, patient's global assessment were found. BASDAI did not show the significant difference between AS and nr-axSpA (mean 4,5 $\pm 2,1$ vs $3,9 \pm 2,0$ ), as well CRP (mean CRP $17,33 \mathrm{mg} / \mathrm{l}$ vs $17,75 \mathrm{mg} / \mathrm{l}$ (p $0,2)$ and ESR.

Conclusions: Diagnosis of axial SpA in Lithuania remains delayed. The proportion of patients with AS among newly diagnosed axial $\mathrm{SpA}$ is high.There are more women in the $\mathrm{nr}$-axSpA group. Both groups do not differ regarding clinical features, disease activity.

\section{References:}

[1] Adomaviciute D, Pileckyte M, Baranauskaite A, Morvan J, Dadoniene J, Guillemin F.Scand J Rheumatol. 2008 Mar-Apr;37(2):113-9 Prevalence survey of rheumatoid arthritis and spondyloarthropathy in Lithuania.

Disclosure of Interest: None declared

DOI: 10.1136/annrheumdis-2017-eular.6944

\section{AB0720 CHARACTERISTICS OF TUNISIEN SPONDYLOARTHRITIS PATIENTS WITH HIP DISEASE}

K. Maatallah ${ }^{1}$, F. Essafi ${ }^{1}$, I. Mahmoud ${ }^{2}$, K. Ben Abdelghani $^{3}$, O. Saidane ${ }^{2}$ W. Hamdi ${ }^{1}$, M.M. Kchir ${ }^{1}$, R. Tekaya ${ }^{2}$, L. Abdelmoula ${ }^{2} .{ }^{1}$ Rheumatology, MOHAMED KASSAB Orthopedics National Institute, manouba; ${ }^{2}$ Rheumatology, Charles Nicolle hospital; ${ }^{3}$ Rheumatology, Monji Slim hospital, tunis, Tunisia

Background: spondyloarthritis ( $\mathrm{SpA})$ is characterized by inflammation of spine and sacroiliac joints. Hip involvement is the most frequent extra spinal arthritic manifestation of $\mathrm{SpA}$ and may lead to a worse functional outcome.

Objectives: The objective of this study was to assess clinical, biological and radiological characteristics of $\mathrm{SpA}$ patients with hip disease.

Methods: This is a transversal multicenter study, including SpAs patients (satisfying ASAS criteria2009) with hip disease Demographic, clinical, radiographic, and laboratory data were collected and analyzed. Radiographic forms of hip disease were assessed according to Netter classification (early, condensing, destructive, combined and synostosante forms). Radiographic severity was assessed by the modified Stokes Ankylosing Spondylitis Spine Score (mSASSS) and BASRI (Bath Ankylosing Spondylitis Radiologic Index).

Results: ninety four patients were evaluated (77men). The mean age was $41.53 \pm 11.97$ years. The median age at disease onset was $26.23 \pm 10.29$ years. The mean diagnostic delay was 6.48 years. $46 \%$ of patients were smoker. HLA B27 was positive in $50 \%$ of cases. A peripheral joint involvement was found in $33 \%$ of cases. Extra-articular manifestation was seen in $57 \%$ of patients: osteoporosis (16 patients), uveitis (15 patients), psoraisis (10 patients), chronic inflammatory bowel disease (12 patients). 78 patients had bilateral hip involvement and 147 hips were evaluated. The median BASDAI and BASFI scores were respectively 5,4 and 5,5. The mean index of severity for osteoarthritis for the hip (ISH) was $12.24( \pm 6.84)$. Patients had an early form of hip disease in $22 \%$ of cases, Condensing form in $3 \%$ of cases, combined forms in $22 \%$ of cases and destructive form in $53 \%$ of cases. BASRI-hip score was 1 in $24 \%, 2$ in $49 \%, 3$ in $19 \%$ and 4 in $8 \%$ of hips. Sacoiliac joint grade was 2 in $17 \%, 3$ in $37 \%$ and 4 in $46 \%$ of cases. The mean mSASSS score was $15.34 \pm 16.22$

TNF inhibitors were indicated in $49 \%$ of patients (infliximab 23, Adalimumab 7 and Etanercept 18).31 patients received csDMARDs and 46 NSAID.
Conclusions: Our finding confirm previous observation that clinical and radiological hip involvement is associated with a more severe disease with a high activity and pronounced functional impairments.

Disclosure of Interest: None declared

DOI: 10.1136/annrheumdis-2017-eular.5099

\section{AB0721 THE EVALUATION OF ULTRASONOGRAPHIC AND CLINICAL ENTHESOPATHY IN PATIENTS WITH INFLAMMATORY RHEUMATIC DISEASES}

E. Suleyman ${ }^{1}$, H. Harman ${ }^{2}$, K. Nas ${ }^{1}$. ${ }^{1}$ Division of Rheumatology and Immunology, Department of Physical Medicine and Rehabilitation, Sakarya University, Faculty of Medicine, Sakarya; ${ }^{2}$ Rheumatology Clinic, Bolu Izzet Baysal State Hospital, Bolu, Turkey

Background: Enthesitis is considered as the primary anatomical lesion in spondyloarthropathy ( $\mathrm{SpA}$ ) but it can be seen in other rheumatologic diseases. Its locations and clinical relationships have not been studied well in the literature. Objectives: We aimed to investigate the frequency of ultrasonographic, clinical enthesopathy and the relationship between enthesopathy and disease activity, functional status in patients with rheumatoid arthritis (RA) and axial SpA.

Methods: Thirty three axial SpA, 21 RA patients and 30 healthy subjects were included in the study. The clinical and functional evaluations relied on the BASDAI, BASFI, ASQoL, DAS28, and HAQ, and on a VAS for entheseal pain, as well as on the MASEI. Knee, ankle and elbow were examined with US bilaterally in 172 joint regions.

Results: The physical examination scores for enthesitis were $1.97 \pm 2.68$, $2.43 \pm 1.80,0.23 \pm 0.12$ in axial $\mathrm{SpA}$, RA and healthy subjects, respectively. There was no statistically significant difference between axial SpA and RA about enthesitis physical examination scores $(p=0.123)$. A statistically significant difference was not found between axial SpA and RA in quadriceps tendon enthesitis and distal patellar ligament enthesitis according to MASEI index (MASEI 3,4,5) $(p=0.993, p=0.124, p=0.652)$. Other MASEI enthesit scores were statistically higher in axial SpA group than RA and healthy subjects $(p=0.008)$. Positive correlations were found between BASDAI scores and enthesitis pyhsical examination scores, MASEI total scores $(r=0.739, p=0.0001, r=0.516, p=0.002)$. There was moderately positive correlation between ASQoL total scores and MASEI total scores $(r=0.466, p=0.006)$. HAQ total scores were not correlated with MASEI total scores $(r=0.213, p=0.065)$.

Conclusions: Ultrasonographic enthesitis was associated with impaired quality of life in axial SpA. MASEI 1 and 2 was spesific entheseal regions in MASEI index for axial SpA. Different from RA, the calcaneal enthesitis region for clinical investigation and ultrasonographic enthesopathy should be focused on in axial SpA.

Disclosure of Interest: None declared

DOI: 10.1136/annrheumdis-2017-eular.6834

\section{AB0722 THE IMPACT OF A REFERRAL STRATEGY FOR AXIAL SPONDYLOARTHRITIS IN YOUNG PATIENTS WITH CHRONIC LOW BACK PAIN: SHORT TERM OUTCOMES OF THE IMPACT STUDY}

L. Van Hoeven ${ }^{1,2}$, A. Korver ${ }^{1,2}$, C. Appels ${ }^{3}$, J. Hazes ${ }^{1}$, F. van den Hoogen ${ }^{4}$, M. van Oosterhout ${ }^{5}$, J. Oostveen ${ }^{6}$, J. Spoorenberg ${ }^{7}$, I. Tchetverikov ${ }^{8}$, T. Kuijper ${ }^{2}$, B. Koes ${ }^{9}$, A. Weel ${ }^{1,2}$. ${ }^{1}$ Rheumatology, Erasmus University Rotterdam; ${ }^{2}$ Rheumatology, Maasstad Hospital, Rotterdam; ${ }^{3}$ Rheumatology, Amphia Hospital, Breda; ${ }^{4}$ Rheumatology, Sint Maartenskliniek, Ubbergen; ${ }^{5}$ Rheumatology, Groene Hart Hospital, Gouda; ${ }^{6}$ Rheumatology, ZGT, Almelo; ${ }^{7}$ Rheumatology, UMCG, Groningen; ${ }^{8}$ Rheumatology, Albert Schweitzer Hospital, Dordrecht; ${ }^{9}$ Primary Care, Erasmus University Rotterdam, Rotterdam, Netherlands

Background: A substantial amount of young patients with chronic low back pain (CLBP) have axial spondyloarthritis (axSpA), but early recognition of these patients is difficult for general practitioners (GPs). Recently, the CaFaSpA referral rule has been published and externally validated. It is an easy to use referral strategy that has shown to be able to identify patients with CLBP at high risk for axSpA in a primary care setting. The CaFaSpA referral rule consists of 4 items: inflammatory back pain, family history of axSpA or related disease, good reaction to NSAIDs and duration of back pain $\geq 5$ years. If at least 2 out of 4 items are present, the referral rule is positive and a referral to a rheumatologist is advised. Objectives: To assess the effect of the CaFaSpA referral rule on disability in young CBPP patients by comparing it with usual care, using the format of an impact analysis.

Methods: A cluster randomized controlled trial with GP practices as clusters GP practices were randomized to either the intervention (use of the referral strategy) or control (usual care) group. Within these GP practices, patients aged 18-45 years with current CLBP were recruited. The primary outcome was disability caused by low back pain, measured with the Roland Morris Disability Questionnaire (RMDQ) scale 0-24. RMDQ score was obtained at baseline and 4 months after a referral advice was made. A higher RMDQ score means more disability. For statistical analysis a linear mixed effects regression model was used. 